\title{
Employment status and sick-leave following obesity surgery: a five-year prospective cohort study
}

John Roger Andersen, Ulrikke J.V. Hernæs, Karl Ove Hufthammer, Villy Våge

Background. Severe obesity is a risk factor for lower participation in paid work, but whether employment increases and sick leave decreases after obesity surgery is not well documented. Methods. We assessed 224 Norwegian patients with severe obesity (mean age: 40; mean BMI: 49; 61\% female) regarding employment status (working versus not working) and the number of days of sick leave during the preceding 12 months, before and five years after obesity surgery (75\% follow-up rate). Logistic regression analysis was used to study preoperative predictors of employment status after surgery. Results. There were no change in the employment rate over time (54\% versus $58 \%$ ), but the number of days of sick leave per year was significantly reduced, from a mean of 63 to a mean of 26 , and from a median of 36 to a median of 4 . Most of this change was attributable to patients with zero days of sick leave, which increased from $25 \%$ to $41 \%$. Being female, older, having low education level, receiving disability pension and not being employed before obesity surgery were important risk factors for not being employed after obesity surgery. The type of obesity surgery, BMI and marital status were not useful predictors. Conclusions. Our findings suggest that that undergoing obesity surgery is not associated with a higher rate of employment, although it may reduce the number of days of sick leave. Additional interventions are likely needed to influence the employment status of these patients. The significant preoperative predictors of not being employed in this study provide suggestions for further research . 


\section{Employment status and sick-leave following obesity surgery: \\ 2 a five-year prospective cohort study}

3 John Roger Andersen ${ }^{1,2}$, Ulrikke J. V. Hernæs ${ }^{1,3}$, Karl Ove Hufthammer ${ }^{4}$, Villy Våge ${ }^{1,5}$

$4 \quad{ }^{1}$ Centre of Health Research, Førde Hospital Trust, Førde, Norway

$5 \quad{ }^{2}$ Department of Health Studies, Sogn og Fjordane University College, Førde, Norway

$6 \quad{ }^{3}$ Department of Research and Development, Haukeland University Hospital, Bergen, Norway

$7 \quad{ }^{4}$ Centre for Clinical Research, Haukeland University Hospital, Norway

$8 \quad{ }^{5}$ Department of Surgery, Voss Hospital, Helse Bergen Health Trust, Norway

9 Correspondence: John Roger Andersen. Department of Health Studies, Sogn og Fjordane

10 University College, Førde, Norway. Address: Svanehaugvegen 1, 6812 Førde, Norway.

11 Telephone: +47 48278 186. Email: johnra@hisf.no

12

13 Key words: work, employment, sick-leave, obesity, bariatric surgery, predictors 


\section{Abstract}

15 Background. Severe obesity is a risk factor for lower participation in paid work, but whether

16 employment increases and sick leave decreases after obesity surgery is not well documented.

17 Methods. We assessed 224 Norwegian patients with severe obesity (mean age: 40; mean BMI: $49 ; 61 \%$ female) regarding employment status (working versus not working) and the number of

19 days of sick leave during the preceding 12 months, before and five years after obesity surgery 20 (75\% follow-up rate). Logistic regression analysis was used to study preoperative predictors of 21 employment status after surgery.

22 Results. There were no change in the employment rate over time ( $54 \%$ versus $58 \%$ ), but the 23 number of days of sick leave per year was significantly reduced, from a mean of 63 to a mean of 2426 , and from a median of 36 to a median of 4 . Most of this change was attributable to patients with zero days of sick leave, which increased from $25 \%$ to $41 \%$. Being female, older, having low

26 education level, receiving disability pension and not being employed before obesity surgery were 27 important risk factors for not being employed after obesity surgery. The type of obesity surgery, 28 BMI and marital status were not useful predictors.

29 Conclusions. Our findings suggest that undergoing obesity surgery is not associated with a

30 higher rate of employment, but may reduce the number of days of sick leave. Additional

31 interventions are likely needed to influence the employment status of individuals who undergo

32 obesity surgery. Providing patients with education and targeted vocational rehabilitation are 33 potentially useful interventions. 


\section{Introduction}

35 Severe obesity, defined as having a body mass index (BMI) $\geq 40.0$ or having obesity-related

36 diseases and a $\mathrm{BMI} \geq 35$, has been associated with lower employment rates, largely because of

37 the detrimental effect of obesity on health (Andersen et al. 2010; Gripeteg et al. 2012; Hawkins

38 et al. 2007; Hernæs et al. 2014; Neovius et al. 2008). Studies have also shown that obese subjects

39 are at increased risk for being discriminated against when applying for jobs, for being passed

40 over for promotion and for being made redundant (Puhl \& King 2013). Thus, obesity has

41 economic consequences both on an individual level and for families (Lund et al. 2011; Puhl \&

42 King 2013). Consequently, increasing participation in paid work can be an important effect of

43 the treatment of severe obesity. Such treatment can not only improve the well-being of

44 individuals and their families, but also reduce the increasing indirect obesity-related financial

45 costs faced by many societies (Lehnert et al. 2013).

46 Obesity surgery can be successful in terms of weight loss, the resolution of comorbidities and

47 improvements in quality of life (Andersen et al. 2014; Colquitt et al. 2009). One hypothesis is

48 that obesity surgery also leads to higher rates of employment; however, this is not well

49 documented. Several studies (Andersen et al. 2010; Hawke et al. 1990; Hawkins et al. 2007;

50 Martin et al. 1991; Narbro et al. 1999; Turchiano et al. 2014; Wagner et al. 2007), but not all

51 (Crisp et al. 1977; Gripeteg et al. 2012; Velcu et al. 2005), have suggested an overall positive

52 effect of obesity surgery on employment status or sick leave. However, these studies were

53 limited by small sample sizes $(N<80)$ (Andersen et al. 2010; Crisp et al. 1977; Hawkins et al.

54 2007; van Gemert et al. 1999; Velcu et al. 2005; Wagner et al. 2007), follow-up periods < 5

55 years (Andersen et al. 2010; Crisp et al. 1977; Hawke et al. 1990; Hawkins et al. 2007; Martin et

56 al. 1991; Turchiano et al. 2014; van Gemert et al. 1999; Wagner et al. 2007) or by the use of 
57 outdated obesity surgery procedures such as ileojejunal bypass, non-adjustable gastric banding

58 and vertical banded gastroplasty (Crisp et al. 1977; Gripeteg et al. 2012; Hawke et al. 1990;

59 Narbro et al. 1999; van Gemert et al. 1999). We also know little regarding preoperative

60 predictors of employment status after obesity surgery. Providing additional information on these

61 issues may be useful for further research on how to assist patients undergoing bariatric surgery to

62 obtain and sustain participation in paid work.

63 In this paper we study employment status and sick leave before and five years after obesity

64 surgery. We also study whether preoperative age, sex, marital status, education level, BMI,

65 receipt of disability pension, employment status and type of obesity surgery predicted

66 employment status five years after obesity surgery.

\section{Material \& Methods}

68 Patients 18 years of age or older who were accepted for bariatric surgery at Førde Central

69 Hospital in Norway between 2001 and 2008 were invited to participate in a prospective cohort

70 study. Data were collected before and five years after surgery. The patients underwent

71 biliopancreatic diversion with duodenal switch (BPD/DS), sleeve gastrectomy (SG), gastric

72 bypass (GBP) or a conversion to BPDS/DS from gastric banding. During the first years of this

73 study, BPD/DS was the primary choice of surgery at the hospital. This later changed to SG, as a

74 part of a two-stage strategy, in which BPD/DS is regarded as a last-resort operation.

75 The study conforms to the principles outlined in of the Declaration of Helsinki and was approved

76 by the Regional Committee for Medical and Health Research Ethics in Western Norway (REK

77 vest, ref. nr. 2013/1747). 
78

79

80

81 to estimate their average percentage position in paid work $(0-100 \%)$. They also reported the

82 number of days with sick leave in the preceding 12 months. The validity of assessing this

83 information by self-report has been shown to be good in the Norwegian general population

84 (Myrtveit et al. 2013). Income that came from paid work at the time of the question (coded as yes 85

\section{Assessments}

Employment status and days of sick leave were assessed by self-report questionnaires. The patients were asked whether any of their income came from paid work (coded as yes or no) and or no) was further validated by correlating this variable with the actual income based on public data from the Norwegian Tax Administration (Spearman rank correlation $=0.87, p<0.001$ ) in a random subsample of the patients $(n=20)$.

Body weight was measured in light clothing without shoes, with a precision of 100 grams. Height was measured in a standing position without shoes, with a precision of 1 centimetre. Weight and height were used to calculate the BMI $\left(\mathrm{kg} / \mathrm{m}^{2}\right)$. We also assessed the patients age, sex, marital status (married/cohabiting or not), education level (primary school, high school or university/college) and whether the patients received any disability pension at the time of the question (coded as yes or no).

\section{Statistics}

We performed the statistical analyses using IBM SPSS version 22.0 for Windows and R version 3.1.1 for Windows (R Core Team 2014). All reported $p$-values are 2-sided, and $p$-values $\leq 0.05$ are considered statistically significant. Continuous variables are reported as means, standard deviations, quartiles and/or 95\% confidence intervals, whereas categorical variables are reported as counts and percentages. We used paired $t$-tests to test changes in continuous variables, and 
100 McNemar's test to test changes in binary variables. To explore predictors of unemployment, we

101 fitted logistic regression models with employment status after five years as the dependent

102 variable. Explanatory factors were the preoperative variables age, sex, marital status, education

103 level, BMI, receipt of a disability pension, employment status and type of surgery. Age and BMI

104 were included in the analysis as continuous variables after testing for non-linearity. To detect any

105 problems with multicollinearity in the predictors, we examined the generalised variance-inflation 106 factors.

\section{Results}

108 By the five-year follow-up, we had employment data on 224 patients (75\% follow-up rate)

109 (Fig. 1, Table 1). The overall rate of employment did not change over time, and was $54 \%$ at

110 baseline and $58 \%$ at follow-up ( $p=0.34$; Table 2). Most individuals were either unemployed or

111 worked full-time ( $83 \%$ at baseline and $82 \%$ at follow-up), and the mean full-time equivalent (i.e.,

112 the proportion of income that came from paid work) did not change over time ( 0.46 at baseline

113 and 0.49 at follow-up; $p=0.54$; Table 2). However, there were changes in employment status of

114 the individual patients. Of the 102 patients who were not employed before surgery, $31(30 \%)$ had

115 become employed after five years, and of the 122 patients who were employed before surgery,

11623 (19\%) had lost their employment after five years (Fig. 2).

117 Secondary stratified analyses showed that the employment rate in patients who received (some)

118 disability pension before surgery $(n=70)$ was $17 \%$ at baseline and $21 \%$ at follow up $(p=0.55)$,

119 while it was $71 \%$ at baseline and $74 \%$ at follow-up $(p=0.64)$ in patients who did not receive any

120 disability pension before surgery $(n=146)$. We also found that the proportion of patients 
121 receiving disability pension did not change significantly (32\% at baseline and $38 \%$ at follow up;

$122 p=0.16)$.

123 Although the overall rate of employment remained unchanged, the number of days of sick leave

124 per year was much reduced (Table 2). For patients who were employed at both time points, there

125 was a reduction from a mean of 56 to a mean of $28(p=0.002)$ and from a median of 40 to a

126 median of 5. Note that these estimates could be biased, as one might expect that the patients

127 losing their job from baseline to follow-up (and thus not included in the above calculations) were

128 patients with a large number of days of sick leave. We therefore also report the mean number of

129 days at each time point (for all patients employed at each time point). The results are very

130 similar, a reduction from 63 days to 26 days (means) or from 36 to 4 (medians). Most of this

131 change was attributable to patients with zero days of sick leave, which increased from $25 \%$

$132(27 / 108)$ at baseline to $41 \%(46 / 113)$ at follow-up.

133 From the multiple logistic regression analysis we found that being female, being older, having a

134 low education level (only primary school), receiving disability pension and/or not participating

135 in paid work before surgery were important risk predictors for not being employed after obesity

136 surgery. Marital status, BMI and type of obesity surgery were not useful as predictors (Table 3a).

137 The predictor estimates did not change substantially when adjusted for other predictors, and the

138 predictors showed good explanatory power (Tjur's $D=0.45)$ (Tjur 2009).

139 One could be concerned that the patients receiving disability pension has a very high risk of

140 remaining unemployed, and therefore should be excluded from any analyses looking at

141 predictors of being employed. As a sensitivity analysis, we therefore repeated the analysis but 
142 restricted to the patients not receiving any disability pension (Table $3 b$ ). The results are very

143 similar to the ones based on complete data.

144 Of the 224 patients analysed above, 119 patients also had BMI data at follow-up. For these

145 patients the mean BMI changed from 49.4 (SD: 8.0; CI: 48.3-50.5) at baseline to 31.3 (SD: 5.5;

146 CI: 30.6-32.0) five years after surgery $(p<0.001)$ (Fig. 3). The change in BMI ranged from -0.5

147 to 40.5 . The mean percent BMI loss was 35.8 (SD: 11.6).

\section{Discussion}

149 The rate of employment in this cohort was much lower both before (54\%) and five years after 150 obesity surgery (58\%) than in the general Norwegian population (83\%) with similar age and

151 gender distribution (Andersen et al. 2010). Even though the employment rate did not increase

152 after obesity surgery, the number of days of sick leave decreased significantly.

153 The previous literature on the effect of obesity surgery on employment status and sick leave

154 shows mixed results. However, direct comparisons with our study are difficult, due to clinically

155 and methodological differences (especially in the length of follow-up) and because the social

156 context in other studies may have influenced work availability, access to social benefits and paid

157 sick leave. Regarding long-term studies ( $\geq 5$ years) we have only identified two studies other

158 than ours that have reported participation or indicators of participation in paid work both before

159 and after obesity surgery (Gripeteg et al. 2012; Velcu et al. 2005). The stable employment rate in

160 the present study is comparable to findings of a US study (Velcu et al. 2005) that followed 41

161 patients who underwent GBP for five years, in which the rate of employment exhibited a

162 statistically non-significant improvement from $34 \%$ to $44 \%(p=0.13)$. Finally, in a Swedish 
163 study bariatric surgery was associated with a $17 \%(p=0.01)$ reduction in disability pension for

164 up to 19 years in men but not in women (Gripeteg et al. 2012).

165 The reduction in sick leave in the present study was large, and suggests that productivity was

166 increased due to health benefits among those who had a paid job. We have not identified other

167 long-term studies ( $\geq 5$ years) on sick leave after obesity surgery. However, our findings are in

168 agreement with a Swedish study reporting that patients aged 47-60 years who had undergone

169 obesity surgery had $16 \%(p<0.001)$ fever sick days than controls $2-3$ years postoperatively

170 (Narbro et al. 1999). However, no effect was found for patients younger than 47 years. In our

171 study, the reduction in sick leave was not influenced by age (data not reported).

172 Our finding that preoperative status with respect to employment and disability pension predicted

173 employment status after obesity surgery was as expected. Our study also suggests that being

174 female, being older, having low education level (only primary school) and being unemployed or

175 receiving disability benefits before surgery are important risk factors for not being employed

176 after obesity surgery. Of these risk factors, only low education is modifiable. Thus, providing

177 patients with education and targeted vocational rehabilitation might be a useful intervention.

178 The strengths of the present study are the long follow-up period and an acceptable attrition rate.

179 Furthermore, the surgery procedures represent modern obesity surgery. However, the study also

180 has certain limitations. First, we did not have a control group. Two previous observational

181 studies examined unemployed patients with severe obesity by comparing outcomes in patients

182 who underwent obesity surgery versus those who did not (Turchiano et al. 2014; Wagner et al.

183 2007). Both studies found a significant improvement in employment rates in the surgical groups.

184 However, we believe that this design may induce bias, as it does not include the possible risk that 
185 the obesity surgery is associated with a reduction in the rate of employment among those who

186 were employed preoperatively. Thus, we believe that our naturalistic study provides more

187 information on outcomes following obesity surgery, as it included all patients, regardless of

188 preoperative employment status. It is possible that the rate of employment would have decreased

189 significantly in a control group that was randomised to not having obesity surgery, especially if

190 the alternative treatment had little effect on the patients' health. To conduct a randomised

191 controlled trial in this field is demanding, both practical and ethically (Sugerman \& Kral 2005).

192 Because obesity surgery is currently the only known effective long-term treatment for severe

193 obesity (Kwok et al. 2014), we likely have to rely on well-conducted prospective cohort studies

194 (Wolfe \& Belle 2014).

195 One other limitation of our study is that our primary outcomes were based on self-reports, and

196 recall bias may have occurred. However, we believe that the face validity regarding employment

197 status at the time of the question is good, as it is quite easy to know whether one is employed in

198 paid work. We also hypothesised that being employed was associated with higher actual overall

199 incomes, and this was supported by the validation approach described in the method section. On

200 the other hand, we think that the information on the number of days of sick leave per year may

201 have been influenced by recall bias. The recall bias could be systematic, for example in the form

202 of an underestimation of the number of days of sick leave only after surgery. However, we

203 believe that it is likely that the degree of recall bias was identical both before and after surgery.

204 Thus, if the recall bias was unsystematic, our finding would remain valid.

205 Finally, we lacked information of the patient's employment status in the years prior to seeking

206 surgical treatment for their obesity. It is not unlikely that long-term preoperative unemployment 
207 is associated with lower chances of getting employed following obesity surgery. Thus, the

208 inclusion of this information would increase the value of future studies.

\section{Conclusions}

210 In conclusion, the employment rate remained stable while the number of days of sick leave was

211 reduced after obesity surgery. The reduction in days of sick leave is encouraging, and should be

212 further studied in terms of replication of results and cost-effectiveness. The significant predictors

213 of employment status in this study offer suggestions for future research. Providing patients with

214 education and targeted vocational rehabilitation are potentially useful interventions. The stories

215 of patients who joined or left the workforce after obesity surgery could be studied using

216 qualitative methods. Finally, we recommend looking for novel additional interventions intended

217 to increase the rate of employment in this patient group.

\section{Acknowledgements}

219 We thank Lisbeth Schelderup and the rest of the staff at the Obesity Clinic at Førde Central

220 Hospital for conducting the data collection of this study. 


\section{References}

223

224

225

226

227

228

229

230

231

232

233

234

235

236

237

238

239

240

241

242

243

244

245

246

247

248

249

250

251

252

253

254

Andersen JR, Aasprang A, Bergsholm P, Sletteskog N, Vage V, and Karin Natvig G. 2010. Health-related quality of life and paid work participation after duodenal switch. Obes Surg 20:340-345.

Andersen JR, Aasprang A, Karlsen TI, Natvig GK, Kolotkin RL, and Våge V. 2014. Healthrelated quality of life after bariatric surgery: a systematic review of prospective long-term studies. Surg Obes Relat Dis http://dx.doi.org/10.1016/j.soard.2014.10.027.

Colquitt JL, Picot J, Loveman E, and Clegg AJ. 2009. Surgery for obesity. Cochrane Database Syst Rev:CD003641.

Crisp AH, Kalucy RS, Pilkington TR, and Gazet JC. 1977. Some psychosocial consequences of ileojejunal bypass surgery. Am J Clin Nutr 30:109-120.

Gripeteg L, Lindroos AK, Peltonen M, Sjostrom L, and Narbro K. 2012. Effects of bariatric surgery on disability pension in Swedish obese subjects. Int J Obes (Lond) 36:356-362.

Hawke A, O'Brien P, Watts JM, Hall J, Dunstan RE, Walsh JF, Slavotinek AH, and Elmslie RG. 1990. Psychosocial and physical activity changes after gastric restrictive procedures for morbid obesity. Aust N Z J Surg 60:755-758.

Hawkins SC, Osborne A, Finlay IG, Alagaratnam S, Edmond JR, and Welbourn R. 2007. Paid work increases and state benefit claims decrease after bariatric surgery. Obes Surg $17: 434-437$.

Hernæs UJ, Andersen JR, Norheim OF, and Vage V. 2014. Work Participation Among the Morbidly Obese Seeking Bariatric Surgery: An Exploratory Study from Norway. Obes Surg.

Kwok CS, Pradhan A, Khan MA, Anderson SG, Keavney BD, Myint PK, Mamas MA, and Loke YK. 2014. Bariatric surgery and its impact on cardiovascular disease and mortality: a systematic review and meta-analysis. Int J Cardiol 173:20-28.

Lehnert T, Sonntag D, Konnopka A, Riedel-Heller S, and Konig HH. 2013. Economic costs of overweight and obesity. Best Pract Res Clin Endocrinol Metab 27:105-115.

Lund RS, Karlsen TI, Hofso D, Fredheim JM, Roislien J, Sandbu R, and Hjelmesaeth J. 2011. Employment is associated with the health-related quality of life of morbidly obese persons. Obes Surg 21:1704-1709.

Martin LF, Tan TL, Holmes PA, Becker DA, Horn J, Mann LD, and Bixler EO. 1991. Preoperative insurance status influences postoperative complication rates for gastric bypass. Am J Surg 161:625-634. 
275

276

277

278

279

280

281

282

283

284

Myrtveit SM, Ariansen AM, Wilhelmsen I, Krokstad S, and Mykletun A. 2013. A population based validation study of self-reported pensions and benefits: the Nord-Trondelag health study (HUNT). BMC Res Notes 6:27.

Narbro K, Agren G, Jonsson E, Larsson B, Naslund I, Wedel H, and Sjostrom L. 1999. Sick leave and disability pension before and after treatment for obesity: a report from the Swedish Obese Subjects (SOS) study. Int J Obes Relat Metab Disord 23:619-624.

Neovius K, Johansson K, Rossner S, and Neovius M. 2008. Disability pension, employment and obesity status: a systematic review. Obes Rev 9:572-581.

Puhl RM, and King KM. 2013. Weight discrimination and bullying. Best Pract Res Clin Endocrinol Metab 27:117-127.

Sugerman HJ, and Kral JG. 2005. Evidence-based medicine reports on obesity surgery: a critique. Int $J$ Obes 29:735-745.

R Core Team. 2014. R: A language and environment for statistical computing. R Foundation for Statistical Computing, Vienna, Austria. Available at http://www.R-project.org/.

Tjur T. 2009. Coefficients of Determination in Logistic Regression Models-A New Proposal: The Coefficient of Discrimination. The American Statistician 64:366-372.

Turchiano M, Saunders JK, Fernandez G, Navie L, Labrador L, and Parikh M. 2014. Bariatric surgery may improve employment status in unemployed, underserved, severely obese patients. Obes Surg 24:692-695.

van Gemert WG, Adang EM, Kop M, Vos G, Greve JW, and Soeters PB. 1999. A prospective cost-effectiveness analysis of vertical banded gastroplasty for the treatment of morbid obesity. Obes Surg 9:484-491.

Velcu LM, Adolphine R, Mourelo R, Cottam DR, and Angus LD. 2005. Weight loss, quality of life and employment status after Roux-en-Y gastric bypass: 5-year analysis. Surg Obes Relat Dis 1:413-416; discussion 417.

Wagner AJ, Fabry JM, Jr., and Thirlby RC. 2007. Return to work after gastric bypass in Medicaid-funded morbidly obese patients. Arch Surg 142:935-940; discussion 941.

Wolfe BM, and Belle SH. 2014. Long-term Risks and Benefits of Bariatric Surgery: A Research Challenge. JAMA. 
Figure 1 (on next page)

Figure 1. Study population flow chart 
Patients with

obesity surgery

$$
n=298
$$

Old enough to be retired at end of follow-up

$$
n=14
$$

Patients eligible

$$
n=284
$$

Patients analysed

Missing employment

\section{status at follow-up}

$$
n=60
$$


Figure 2 (on next page)

Figure 2: Distribution of BMI before and five years after obesity surgery (density plots with jittered strip chart) ( $n=224$ at baseline, $n=219$ at follow-up). 


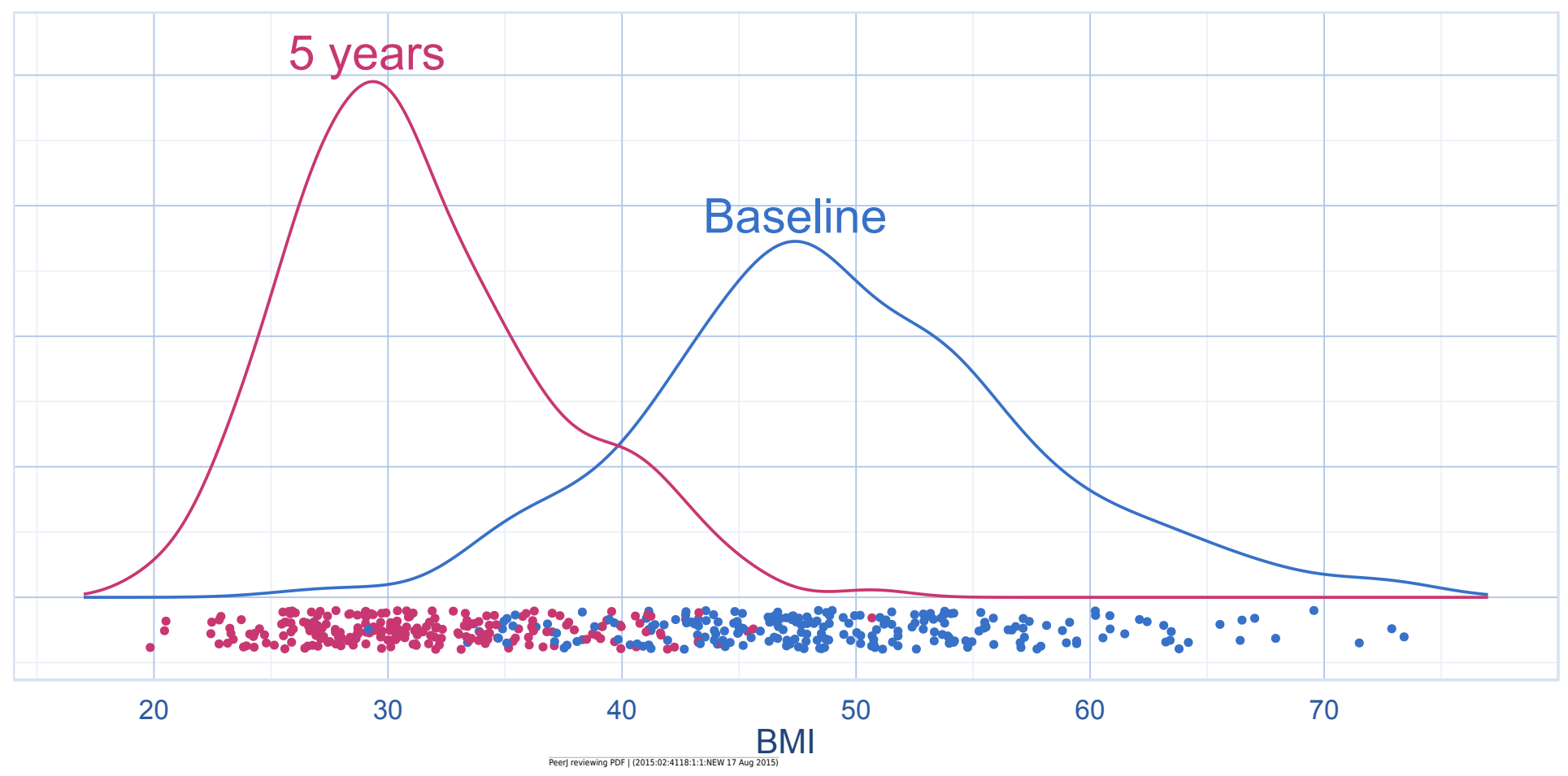


Figure 3 (on next page)

Figure 3: Parallel set plot showing the number and percentage of patients employed before and five years after obesity surgery. The widths of the lines are proportional to the number of patients 


\section{Table 1 (on next page)}

Table 1. Patient characteristics at baseline $(N=224)$ 


\begin{tabular}{lrr}
\hline & Mean/count & SD/(\%) \\
\hline Age & 40 & 9 \\
Sex & & \\
$\quad$ Female & 136 & $(61 \%)$ \\
$\quad$ Male & 88 & $(39 \%)$ \\
Married/cohabitation & 130 & $(58 \%)$ \\
Education $(n=222)$ & & \\
$\quad$ College/university & 56 & $(25 \%)$ \\
$\quad$ High school & 107 & $(48 \%)$ \\
$\quad$ Primary school & 59 & $(27 \%)$ \\
BMI & 49 & 8 \\
Disability pension $(n=216)$ & 70 & $(32 \%)$ \\
Surgery method & & \\
$\quad$ Biliopancreatric diversion with duodenal switch & 154 & $(69 \%)$ \\
$\quad$ Sleeve gastrectomy & 51 & $(23 \%)$ \\
$\quad$ Gastric bypass & 5 & $(2 \%)$ \\
$\quad$ Revisions & 14 & $(6 \%)$ \\
\hline
\end{tabular}


Table 2 (on next page)

Table 2. Employment status and days per years with sick leave before and five years after obesity surgery $(n=224)$

* There was missing data on number of days with sick leave for some patients who stated they were employed (14 patients at baseline and 17patients at follow-up). One patient reported being employed but having 365 days of sick leave. This was truncated to 260 days, the maximum possible number of working days. 
Employed (yes/no), count

Full-time equivalent, mean*

Days with sick leave per year $\dagger$

Patients employed at both

baseline and follow-up (paired $t$ -

test, $n=75$ ), mean

Patients employed at at least one

time point ( $n=108$ at baseline,

\begin{tabular}{rrr}
\multicolumn{3}{c}{ Before operation } \\
Mean/ & $\mathrm{SD} /$ & Quartiles \\
count & $(\%)$ & \\
\hline 122 & $(54 \%)$ & - \\
0.46 & 0.46 &
\end{tabular}

56

$61 \quad 2 ; 40 ; 86.5$

63

\begin{tabular}{rrr}
\multicolumn{3}{c}{5 years after operation } \\
Mean/ & SD/ & Quartiles \\
count & $(\%)$ & \\
\hline 130 & $(58 \%)$ & - \\
0.49 & 0.46 &
\end{tabular}

$P$-value

0.34

0.54

$28 \quad 46 \quad 0 ; 5 ; 39$

26

45

$0 ; 4 ; 35$

$n=113$ at follow-up), mean

\footnotetext{
$1 *$ The fraction of full-time employment, e.g. $0=$ unemployed, $0.5=$ working half time, $1=$ working full time.

$2 \dagger$ There was missing data on number of days with sick leave for some patients who stated they were employed (14 patients at baseline and

317 patients at follow-up). One patient reported being employed but having 365 days of sick leave. This was truncated to 260 days, the

4 maximum possible number of working days.
} 


\section{Table 3(on next page)}

Table $3 a$ and $b$. Logistic regression for the risk of not being employed five years after obesity surgery 
1 Table 3a. Logistic regression for the risk of not being employed five years after obesity surgery $2(n=211)$.

\begin{tabular}{|c|c|c|c|c|c|c|c|c|c|c|}
\hline \multirow[b]{3}{*}{ Age (years) $\dagger$} & \multicolumn{5}{|c|}{ Unadjusted model } & \multicolumn{5}{|c|}{ Adjusted model } \\
\hline & \multirow{3}{*}{$\begin{array}{r}\mathrm{OR}^{*} \\
1.04\end{array}$} & \multicolumn{3}{|c|}{$95 \% \mathrm{CI}$} & \multirow{2}{*}{$\begin{array}{l}P \text {-value } \\
0.01\end{array}$} & \multirow{3}{*}{$\begin{array}{l}\text { OR* } \\
1.05\end{array}$} & \multicolumn{3}{|c|}{$95 \% \mathrm{CI}$} & \multirow{2}{*}{$\begin{array}{r}P \text {-value } \\
0.02\end{array}$} \\
\hline & & 1.01 & to & 1.07 & & & 1.01 & to & 1.10 & \\
\hline Sex & & & & & $<0.01$ & & & & & 0.003 \\
\hline Female (ref.) & 1 & - & to & - & - & 1 & - & to & - & - \\
\hline Male & 0.34 & 0.18 & to & 0.61 & $<0.01$ & 0.31 & 0.13 & to & 0.68 & 0.003 \\
\hline Married/cohabitation & 0.94 & 0.54 & to & 1.64 & 0.83 & 0.83 & 0.38 & to & 1.79 & 0.63 \\
\hline Education & & & & & $<0.001$ & & & & & $<0.001$ \\
\hline University/college (ref.) & 1 & - & to & - & - & 1 & - & to & - & - \\
\hline High school & 1.64 & 0.79 & to & 3.55 & 0.20 & 1.13 & 0.45 & to & 2.90 & 0.80 \\
\hline Primary school & 8.40 & 3.65 & to & 20.56 & $<0.001$ & 6.98 & 2.41 & to & 21.73 & $<0.001$ \\
\hline BMI $\left(\mathrm{kg} / \mathrm{m}^{2}\right) \dagger$ & 1.01 & 0.97 & to & 1.04 & 0.74 & 1.03 & 0.98 & to & 1.08 & 0.30 \\
\hline Disability pension before surgery & 10.56 & 5.39 & to & 21.84 & $<0.001$ & 4.05 & 1.68 & to & 10.07 & 0.002 \\
\hline Not working before surgery & 9.84 & 5.29 & to & 18.96 & $<0.001$ & 6.40 & 2.85 & to & 15.05 & $<0.001$ \\
\hline Treatment + & & & & & 1.00 & & & & & 0.25 \\
\hline $\begin{array}{l}\text { Biliopancreatric diversion } \\
\text { with duodenal switch }\end{array}$ & 1 & - & to & - & - & 1 & - & to & - & - \\
\hline Sleeve gastrectomy & 0.98 & 0.51 & to & 1.89 & 0.96 & 1.59 & 0.63 & to & 4.11 & 0.33 \\
\hline Revisions & 0.98 & 0.31 & to & 2.97 & 0.98 & 0.38 & 0.06 & to & 1.94 & 0.26 \\
\hline
\end{tabular}

3

4 Table 3b. Logistic regression for the risk of not being employed five years after obesity surgery

5 for patients not receiving any disability pension before surgery $(n=144)$.

\begin{tabular}{|c|c|c|c|c|c|c|c|c|c|c|}
\hline \multirow[b]{3}{*}{ Age (years) } & \multicolumn{5}{|c|}{ Unadjusted model } & \multicolumn{5}{|c|}{ Adjusted model } \\
\hline & \multirow{3}{*}{$\begin{array}{l}\mathrm{OR}^{*} \\
1.01\end{array}$} & \multicolumn{3}{|c|}{$95 \% \mathrm{CI}$} & \multirow{2}{*}{$\begin{array}{r}P \text {-value } \\
0.49\end{array}$} & \multirow{3}{*}{$\begin{array}{r}\mathrm{OR}^{*} \\
1.05\end{array}$} & \multicolumn{3}{|c|}{$95 \% \mathrm{CI}$} & \multirow{2}{*}{$\begin{array}{l}P \text {-value } \\
0.05\end{array}$} \\
\hline & & 0.97 & to & 1.06 & & & 1.00 & to & 1.10 & \\
\hline Sex & & & & & 0.11 & & & & & 0.02 \\
\hline Male & 0.54 & 0.25 & to & 1.15 & 0.11 & 0.33 & 0.12 & to & 0.82 & 0.02 \\
\hline Married/cohabitation & 0.91 & 0.43 & to & 1.94 & 0.81 & 0.96 & 0.38 & to & 2.46 & 0.94 \\
\hline Education & & & & & 0.001 & & & & & 0.001 \\
\hline Primary school & 5.39 & 1.88 & to & 16.84 & 0.002 & 5.47 & 1.66 & to & 19.92 & 0.007 \\
\hline BMI $\left(\mathrm{kg} / \mathrm{m}^{2}\right) \dagger$ & 1.04 & 0.99 & to & 1.09 & 0.14 & 1.04 & 0.97 & to & 1.10 & 0.26 \\
\hline Not working before surgery & 4.24 & 1.94 & to & 9.48 & $<0.001$ & 5.01 & 1.96 & to & 13.59 & $<0.001$ \\
\hline Treatment: & & & & & 0.70 & & & & & 0.52 \\
\hline $\begin{array}{l}\text { Biliopancreatric diversion } \\
\text { with duodenal switch }\end{array}$ & 1 & - & to & - & - & 1 & - & to & - & - \\
\hline
\end{tabular}

* OR $>1$ means increased risk for not being employed in paid work five years after obesity surgery.

$\dagger$ Age and BMI were also included as non-linear terms (second-degree polynomials), with no notable changes in any estimated effects or $p$ values. We therefore only report the estimated linear effect.

\$ It was not possible to reliably estimate the effect of gastric bypass, as only 3 (out of 5) patients had complete follow-up data (all of them were employed at follow-up). The gastric bypass patients are therefore excluded from the models. 